\title{
A NUMERICAL ANALYSIS OF THERMAL MANAGEMENT FOR HIGH POWER LED STREET LIGHTS
}

\author{
Burcu Cicek ${ }^{1}$, Necmettin Sahin ${ }^{2}$ \\ ${ }^{1}$ Aksaray University, Department of Mechanical Engineering, Aksaray, 68100, Turkey \\ ${ }^{2}$ Aksaray University, Department of Mechanical Engineering, Aksaray, 68100, Turkey
}

\begin{abstract}
When power is applied to LEDs, the luminance reaction occurs and the energy in light form, which is also known as luminous flux, is released. In the reaction, only a part of the energy is converted into light flux and the remainder becomes heat. During the heat generation, the p-n connection point has the highest temperature in the device. The temperature at this point is called the junction temperature. Junction temperature in LEDs is a very crucial parameter. If the junction temperature exceeds the maximum permissible value, the LED will either fail or be damaged over time. As a result, improper thermal management causes the maximum operating temperature to be exceeded.

In this study, a LED package was designed for street illumination. Thermal behaviours of the designed LED packages and integrated heat sinks and fins in various geometries are simulated by using the Ansys Fluent software. In addition, as a solution to the LED overheating problem, a heat sink with a cylindrical heat pipe was integrated to the LED package and the effect of thermal and geometric properties on thermal behaviour was numerically investigated.
\end{abstract}

Keywords: High-Power LEDs, Heat Pipe, Numerical Simulation, Thermal Management

\section{INTRODUCTION}

Today, light emitting diodes (LEDs) market is one of the most rapidly growing markets. LEDs are replacing conventional light sources such as incandescent lamps and fluorescents, because of their superiority in many properties like efficiency, reliability, short response time, durability, color variability, compactness and lightness. LEDs are used predominantly in LCD backgrounds, monitors, transportation equipment and general illumination. The applications that fall within the general illumination category include outdoor illumination inplaces like streets, bridges, stadiums as well as residential area and industrial illumination [1].

In LEDs, only $20 \%$ of the input electrical energy is converted into light, the rest is converted into heat [2]. During this heat generation, $\mathrm{p}-\mathrm{n}$ junction has the highest temperature within the device. Thus, the temperature at this point is called the junction temperature. In LEDs, junction temperature is of vital importance because the life of the LED and light flux depend on it. Performance of a LED is affected significantly by its thermal and optical behavior.In order to design a high - performance LED application, as the case for other electronic devices, the heat generated has to be effectively removed from the system. The conventional method for heat dissipation in electronic devices is using a fan and a heat sink. Recently, alternative two-phase technologies such as heat pipe and thermosiphon systems are becoming popular. Heat pipe systems are used to dissipate heat from especially medium and high power
LED illuminations. In the literature, there many studies that investigated the usage of heat pipes for cooling the LEDs.

Kim et al. [3] designed two LED models and performed thermal analyses of them. Firstly, they brazed multi LED chip onto the Metal Core Printed Circuit Board (MCPCB)and secondly, they added a heat pipe to this system, thus forming two different models. Lu et al. [4] used a Loop Heat Pipe (LHP) to improve the thermal properties of the LED package. In their study, heat dissipation properties of high power LEDs were examined. Lin et al. [5] experimentally investigated the heat transfer properties of aluminum plated oscillating heat pipes, which are formed of parallel and square canals. They observed that, heat pipes used in LEDs achieved a significant drop in LED temperatures, by natural convection. Shen et al. [6] used MCPCB's instead of FR-4 PCB's in their study, in order to improve heat dissipation and electrical performance of LEDs. Channamallikarjun [7] investigated cooling a central processing unit (CPU) by forced convection. In order to solve cooling problem, heat sinks with plate fins and circular pin fins were produced using different copper alloys and the sinks designs were optimized. In the heat sink with plate fins, CAD was used to obtain a better heat dissipation, analyses were performed in different designs and thus the optimum design was tried to be found. Heat sink thickness, pin thickness, profile and material parameters were considered together due to geometric constraints. Different heat sink designs were modelled in Ansys, which is a commercial software package for CAD and thus temperature distribution was determined. It was reportedthat, the results 
output from Ansys were consistent with the experimental results. At the end of the study, it was seen that replacement of aluminum, which is used for the heat sink material, with copper improved the thermal performance. Tang et al. [8] developed a columnar heat pipe (CHP) lead frame for high power LED packages. CHP lead frame is mounted onto radial aluminum heat sink. 42 high power LED chips are installed directly. The thermal performance, brightness and chromaticity of the LED package were experimentally investigated. Schmid et al. [9] examined the usage of a double pipe heat exchanger as a part of an active air cooling system. Their results reveal that, the benefit in heat dissipation obtained by elongating the lamppost is mainly dependent on the flow rate. Wang et al. [10] used an aluminum radiator model as a heat sink to cool high power LEDs. They observed that, when the heat pipe comes into the play, the difference in temperatures in the upper and the lower parts of the fins is reduced and heat dissipation is improved.

In this study, to assist in cooling the LED, a heat sink with fins and a heat pipe are integrated into the system. This LED package has been designed to be used in a new LED armature model, which is supported within the scope of The "SAN-TEZ" project with code 01066.STZ.2011-2 and different from the current designs, which were registered by the Turkish Patent Institute with number TR 201516393. The effects of material properties and geometric properties on junction temperature are numerically investigated.

\section{MATERIALS AND METHODS}

\subsection{Define of Problem}

In this study, as seen in Fig- 1, for cooling of a LED package with 4 piece of $25 \mathrm{~W}$ LED chips, a U-shaped cylindrical heat pipe is designed. The heat pipe has 3 regions: Evaporator region, adiabatic region and condenser region. Evaporator region's function is transmitting the heat into the condenser. Thus, it is placed onto the cooling plate, which is just in the bottom of the LED package. An aluminum cooling plate is integrated into the condenser region, to enable heat dissipation from the system by convection. Fins are formed on the heat sink to increase the heat transfer surface area.

\subsection{Physical Model}

The properties of the heat sink - fins and the heat pipe are given in table 1 and table 2 , respectively. In table 3 , the structural dimensions and thermal properties of the LED package designed for street illumination are given. $\mathrm{Al}_{2} \mathrm{O}_{3}$ DBC is used to form electric circuit.

Table-1: Heat pipe properties

\begin{tabular}{|l|l|}
\hline Parameter & Value \\
\hline Total heat pipe length & $0.58 \mathrm{~m}$ \\
\hline Heat pipe condenser length & $0.20 \mathrm{~m}$ \\
\hline
\end{tabular}

\begin{tabular}{|l|l|}
\hline Heat pipe evaporator length & $0.10 \mathrm{~m}$ \\
\hline Diameter of heat pipe (D) & $0.010 \mathrm{~m}$ \\
\hline Material of heat pipe & Copper \\
\hline Total heat input & $100 \mathrm{~W}$ \\
\hline $\begin{array}{l}\text { Thermal conductivity of heat } \\
\text { pipe }\end{array}$ & $20000 \mathrm{~W} / \mathrm{m} . \mathrm{K}$ \\
\hline Working Fluid & Water \\
\hline
\end{tabular}

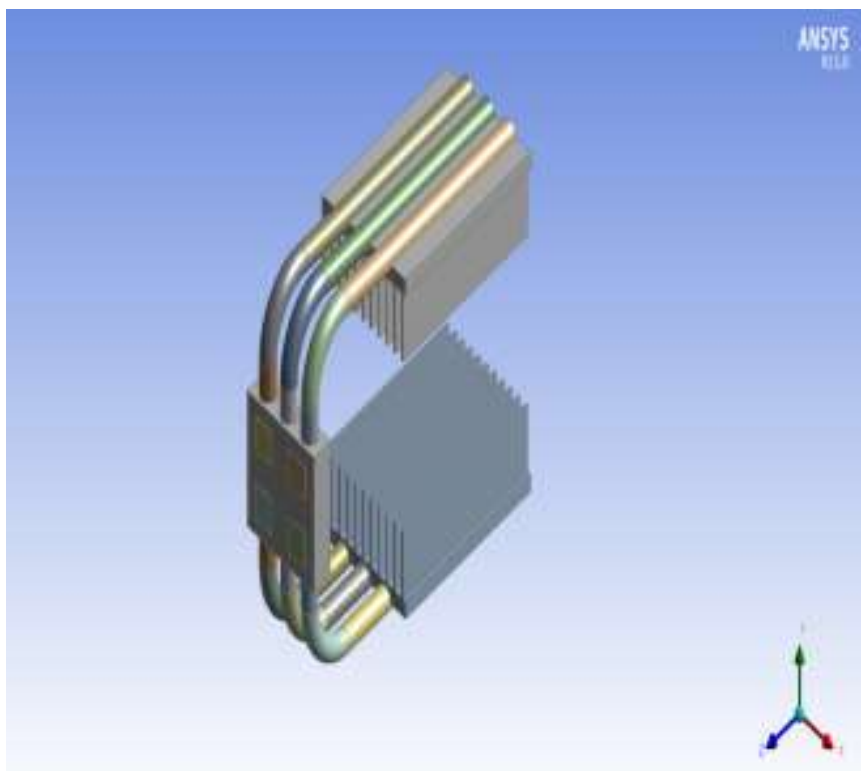

Fig-1: Geometry of designed LED package

Table-2: Properties of heat sink and fins

\begin{tabular}{|l|l|}
\hline Parameter & Value \\
\hline Heat sink length & $0.150 \mathrm{~m}$ \\
\hline Heat sink width & $0.100 \mathrm{~m}$ \\
\hline Distance between two fins & $0.012 \mathrm{~m}$ \\
\hline Fin heigth & $0.035 \mathrm{~m}$ \\
\hline Fin width & $0.001 \mathrm{~m}$ \\
\hline Number of fins & 9 \\
\hline Ambient temperature & $35^{\circ} \mathrm{C}$ \\
\hline
\end{tabular}

Table-3: Dimensions and thermal conductivies of the designed led package

\begin{tabular}{|l|l|l|l|l|}
\hline & $\begin{array}{l}\text { Widt } \\
\mathbf{h} \\
\mathbf{( m m})\end{array}$ & $\begin{array}{l}\text { Dimensi } \\
\text { on }(\mathbf{m m})\end{array}$ & Material & $\begin{array}{l}\text { Thermal } \\
\text { Conductiv } \\
\text { ity(W/m.K } \\
\text { ) }\end{array}$ \\
\hline $\begin{array}{l}\text { LED } \\
\text { Chip }\end{array}$ & 0.6 & $\mathrm{R}=17$ & GaN & 130 \\
\hline $\begin{array}{l}\text { Metalli- } \\
\text { zation }\end{array}$ & 0.01 & $n$ & $\begin{array}{l}\text { Au-Si } \\
\text { eutectic } \\
\text { bonding }\end{array}$ & 27 \\
\hline Die & 0.375 & $n$ & Silicon & 124 \\
\hline $\begin{array}{l}\text { Die- } \\
\text { attach }\end{array}$ & 0.05 & $n$ & Au-20Sn & 57 \\
\hline
\end{tabular}




\begin{tabular}{|l|l|l|l|l|}
\hline $\begin{array}{l}\text { Electro- } \\
\text { nic } \\
\text { circuit } \\
\text { board }\end{array}$ & - & $19 \times 19$ & $\begin{array}{l}\mathrm{Al}_{2} \mathrm{O}_{3} \\
\mathrm{DBC}\end{array}$ & 24 \\
\hline TIM & 0.05 & $19 \times 19$ & $\begin{array}{l}\text { Thermal } \\
\text { Interface } \\
\text { Material }\end{array}$ & 3 \\
\hline $\begin{array}{l}\text { Heat } \\
\text { Sink }\end{array}$ & - & - & Tungsten & 202 \\
\hline
\end{tabular}

\subsection{Methodology}

Heat transfer and fluid flow within the heat pipe are a very complex process. Accordingly, it depends on many factors thermal computational fluid dynamic simulation. The creation of geometric model, integration into the physical domain, mesh generation and selection of an appropriate numerical calculation scheme are important factors that can determine the success level of the simulation process. In this study, thermal analysis of the designed models is numerically solved in three steps in the Ansys 15.0 Fluent program.

\subsubsection{Pre-Processor}

In pre-processor, LED package onto which heat pipe, and heat sink with fins had been integrated was modelled in ANSYS workbench. Then mesh structure was formed. While mesh generation was done, attention has been paid to the creation of mesh structure consisting of trapezoidal (triangular) elements.In the designed model, two nested flow zones were created. While the mesh structure of outer flow zone was straggly, that of inner one was dense. $t$ the end of the mesh structure generation process, 5643861 elements and 1305380 nodes are formed on the model. The minimum element size was selected as $0.20 \mathrm{~mm}$ and It was ensured that the skewness factor value was below 0.96. Mesh structure of the model is shown in detail in Fig- 2.

\subsubsection{Solver}

In solver, the simple method and turbulent mixing length model are used for numeric calculations. When describing the model, the energy equations are kept open and three equationsare used which generally solve the problems of computational fluid dynamics. These are continuity, momentum and energy equations. These three equations are generally called Navier-Stokes equations (Eq. 1-5). The mathematical solution of most fluids is generally calculated in the last two equations. These three equations are shown below respective.

$\underline{\text { Continuity equation }}$

$$
\frac{\partial u}{\partial x}+\frac{\partial v}{\partial y}+\frac{\partial w}{\partial z}=0
$$

Momentum equation

$\underline{\mathrm{x} \text { - momentum equation }}$

$$
\begin{aligned}
\rho\left(u \frac{\partial u}{\partial x}+v \frac{\partial u}{\partial y}+\right. & \left.w \frac{\partial u}{\partial z}\right) \\
& =-\frac{\partial \rho}{\partial x}+\mu\left(\frac{\partial^{2} u}{\partial x^{2}}+\frac{\partial^{2} u}{\partial y^{2}}+\frac{\partial^{2} u}{\partial z^{2}}\right)
\end{aligned}
$$

$\mathrm{y}$ - momentum equation

$$
\begin{aligned}
\rho\left(u \frac{\partial v}{\partial x}+v \frac{\partial v}{\partial y}+\right. & \left.w \frac{\partial v}{\partial z}\right) \\
& =-\frac{\partial \rho}{\partial y}+\mu\left(\frac{\partial^{2} v}{\partial x^{2}}+\frac{\partial^{2} v}{\partial y^{2}}+\frac{\partial^{2} v}{\partial z^{2}}\right)
\end{aligned}
$$

$\underline{\text { z- momentum equation }}$

$$
\begin{aligned}
\rho\left(u \frac{\partial w}{\partial x}+v \frac{\partial w}{\partial y}+\right. & \left.w \frac{\partial w}{\partial z}\right) \\
& =-\frac{\partial \rho}{\partial z} \\
& +\mu\left(\frac{\partial^{2} w}{\partial x^{2}}+\frac{\partial^{2} w}{\partial y^{2}}+\frac{\partial^{2} w}{\partial z^{2}}\right)
\end{aligned}
$$

Energy equation

$$
\begin{aligned}
\left(\mathrm{u} \frac{\partial \mathrm{T}}{\partial \mathrm{x}}+\mathrm{v} \frac{\partial \mathrm{T}}{\partial \mathrm{y}}+\mathrm{w}\right. & \left.\frac{\partial \mathrm{T}}{\partial \mathrm{z}}\right) \\
& =\frac{1}{\alpha}+\mu\left(\frac{\partial^{2} \mathrm{w}}{\partial \mathrm{x}^{2}}+\frac{\partial^{2} \mathrm{w}}{\partial \mathrm{y}^{2}}+\frac{\partial^{2} \mathrm{w}}{\partial \mathrm{z}^{2}}\right)
\end{aligned}
$$

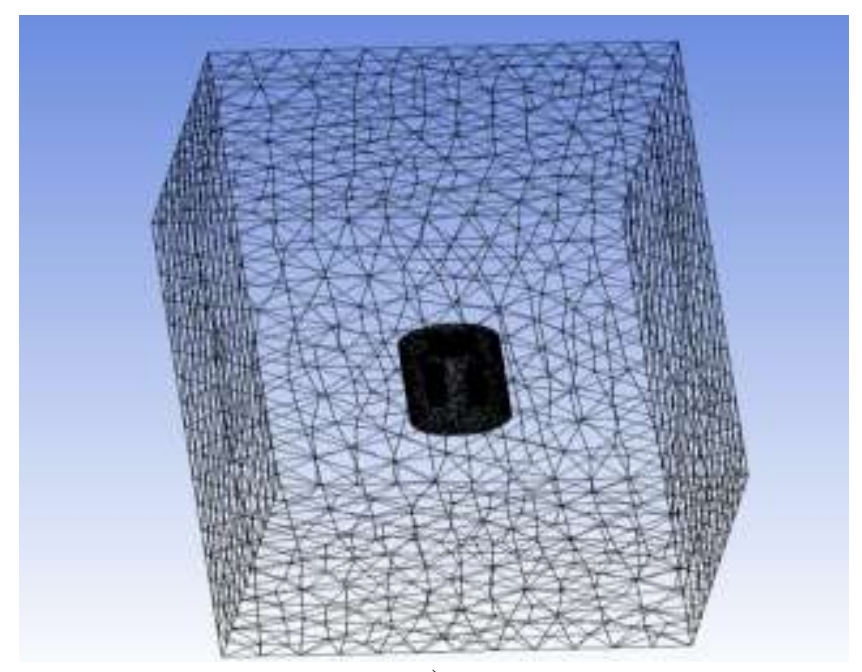

a) 


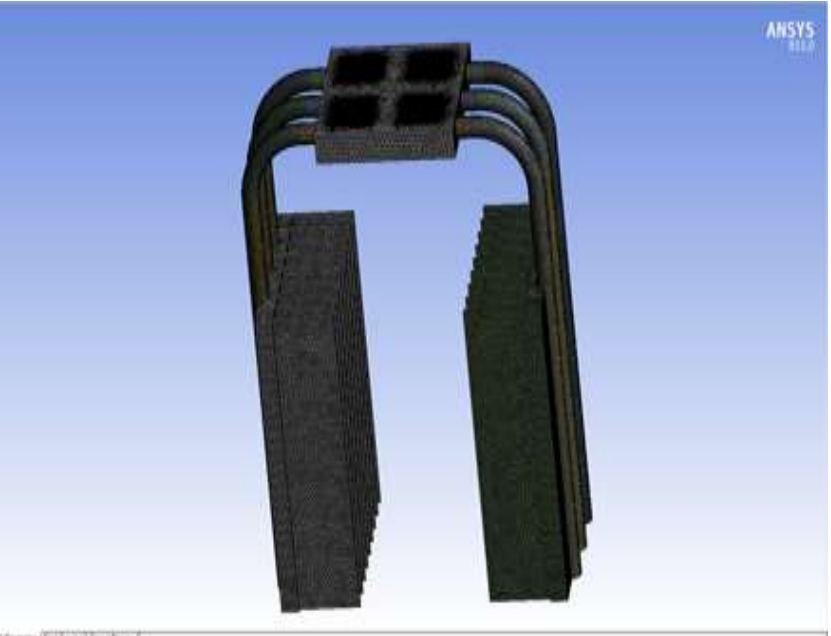

b)

Fig-2: Mesh generation a) with flow zone b)without flow zone of the whole geometry

\subsubsection{Post-Processor}

In the post - processing, the process was clearly visualized and the temperature contours of the system are determined.

\section{NUMERICAL ANALYSIS AND RESULTS}

For cooling electronic systems, the geometry of and material used for the designed model is very important. In this study, the effect of the geometries of the heat sink and the fins, which are integrated into a heat pipe, on the temperature distribution of the whole system was investigated. The length of the heat sink and the profile, height, width, direction and spacing of the fins were modified in attempt to find the optimum heat sink and fin geometry. Thermal analysis results obtained in ANSYS Fluent program are transferred to the graphs by taking the temperature values of the points shown in Fig-3. Accordingly, the maximum temperature at the LED chip is T1, the temperature, which is generated on the top surface of the electronic or printed circuit board is $\mathrm{T} 2$, the evaporator zone temperature is $\mathrm{T} 3$ and T4 and T5 indicate the temperatures at the top and bottom corners of the cooling plate and flap structure, respectively.

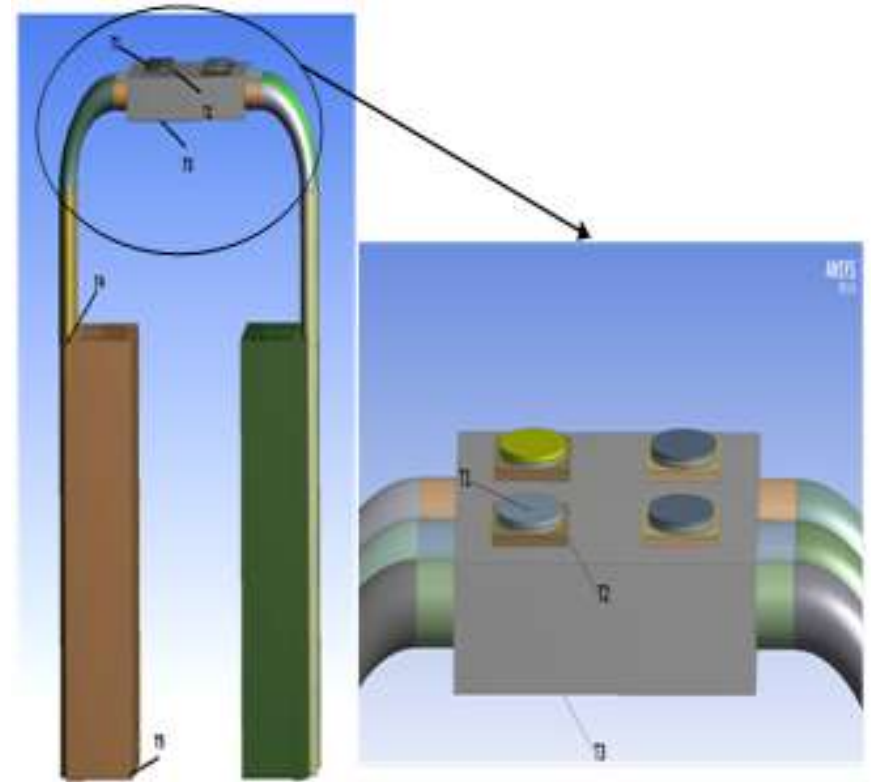

Fig-3: Temperature points stated on the desinged geometry

In Fig- 4, convergence diagram of the thermal analysis in fluent solver is shown. In Fig-5, the resultant temperature distribution of the model designed and solved in ANSYS Fluent program is shown. With reference to this model the heat sink and the fins geometries were changed and the optimum designs were attempted to be found. First square and then circular pin fins on the heat sink were modeled and temperature distributions were generated by ANSYS Fluent (Fig-7 and Fig-9). By observing the temperature distributions generated, it is estimated that the heat transfer is slowed down square and circular pin fin models because of the decreased heat transfer surface areas.

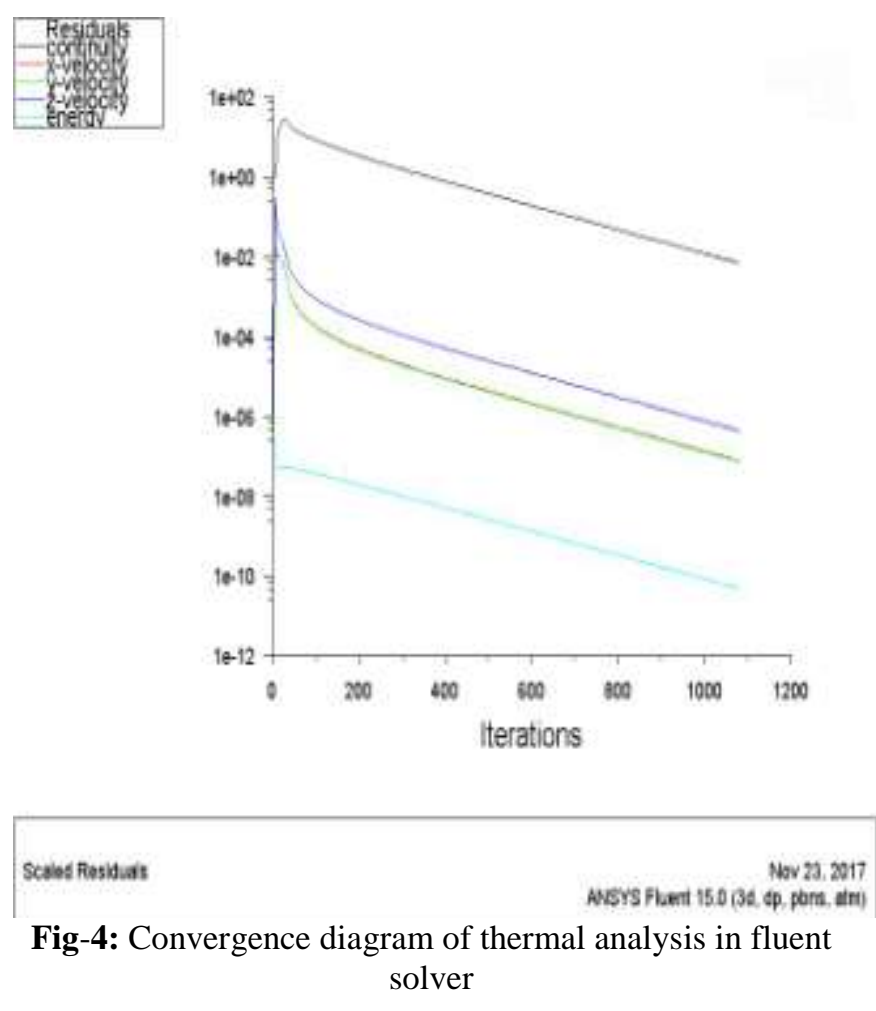




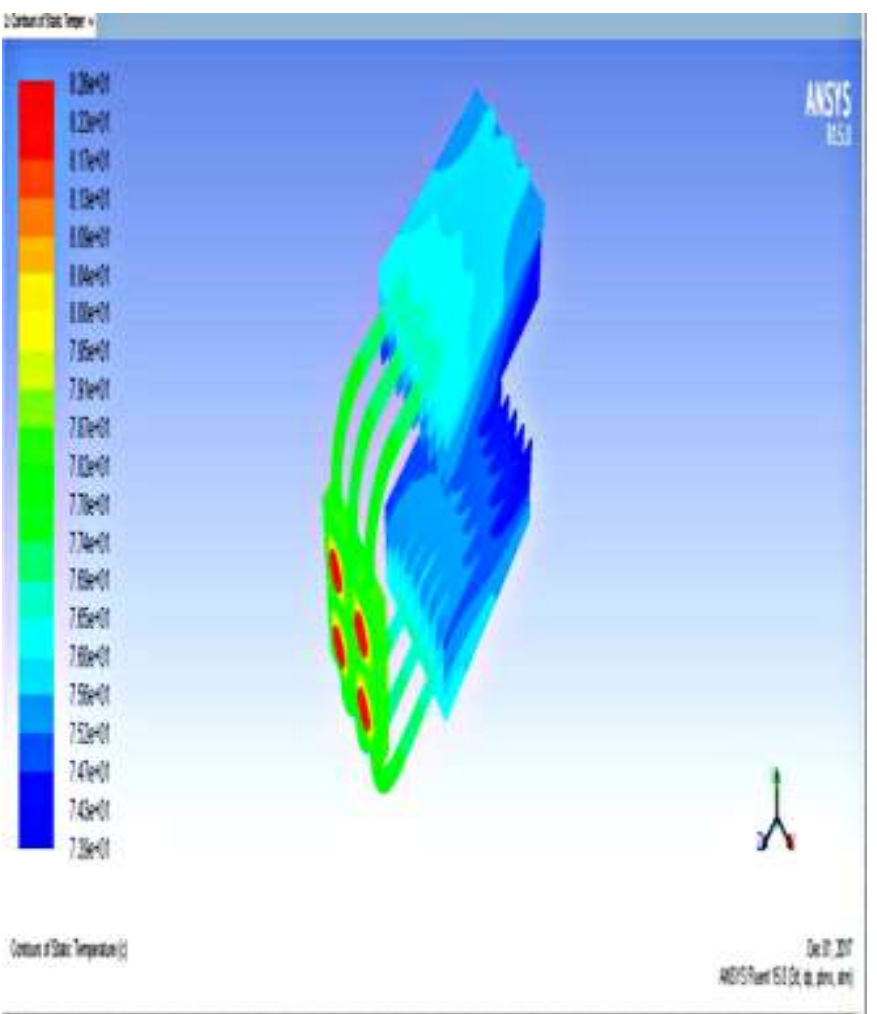

Fig-5: Temperature distribution of the designed model for given boundary conditions.

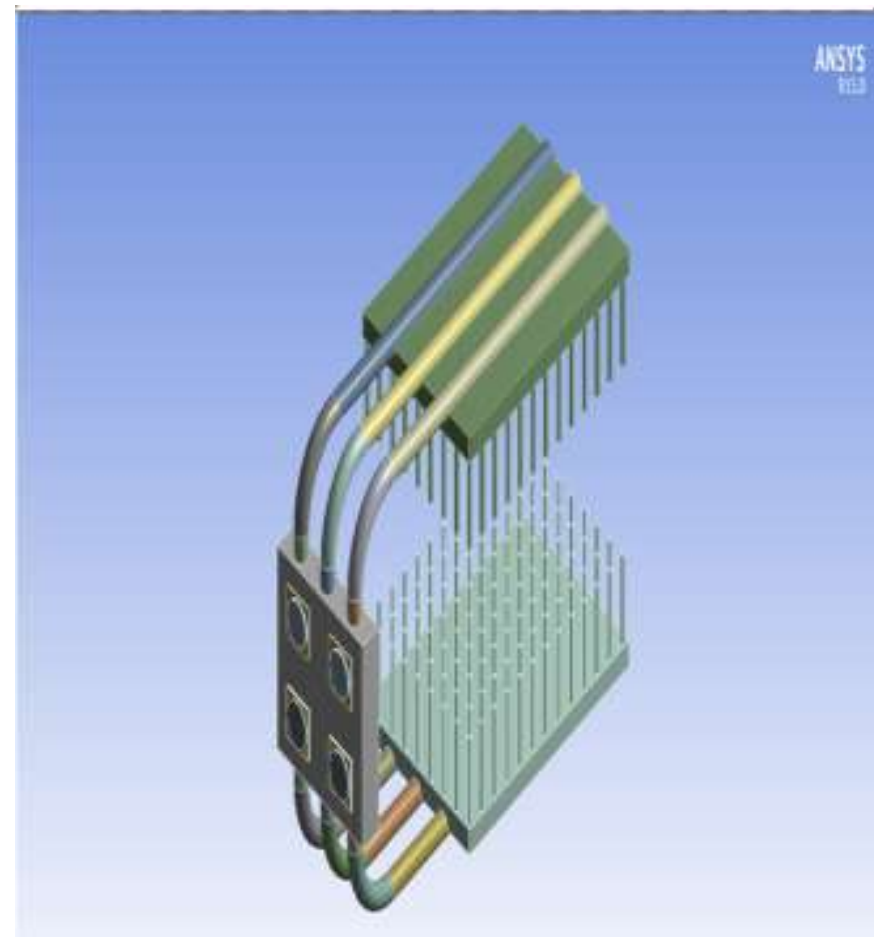

Fig-6: Square pin fin geometry

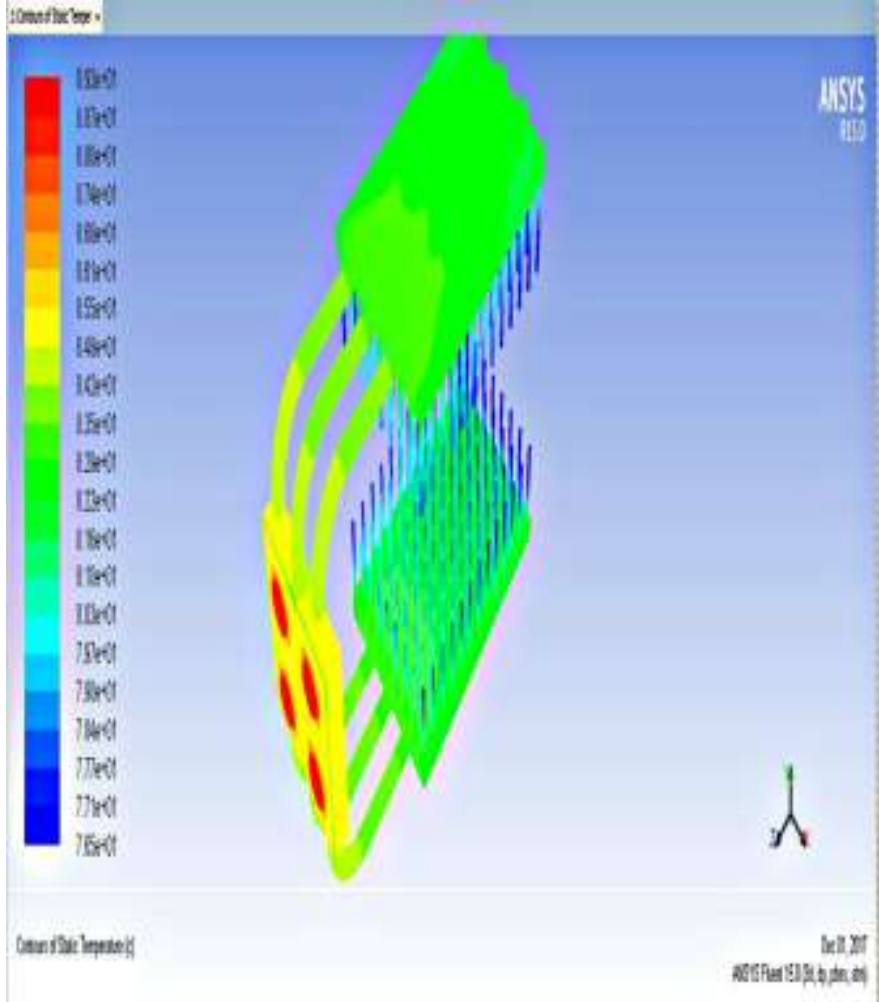

Fig-7: Temperature distribution of square pin fin geometry

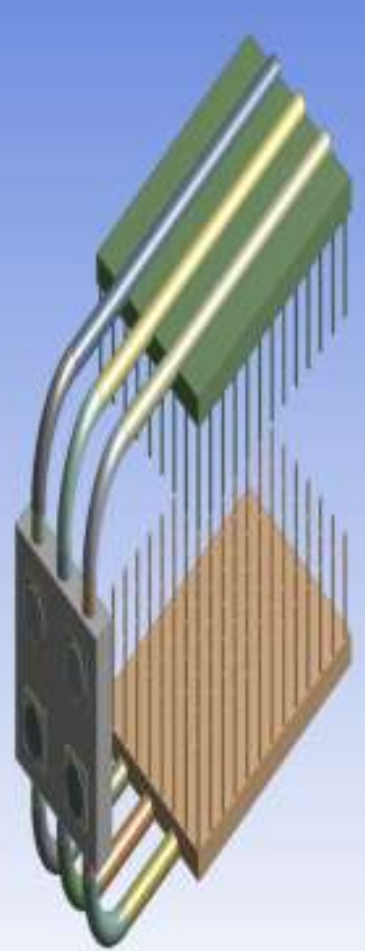

Fig-8: Circular pin fin geometry 


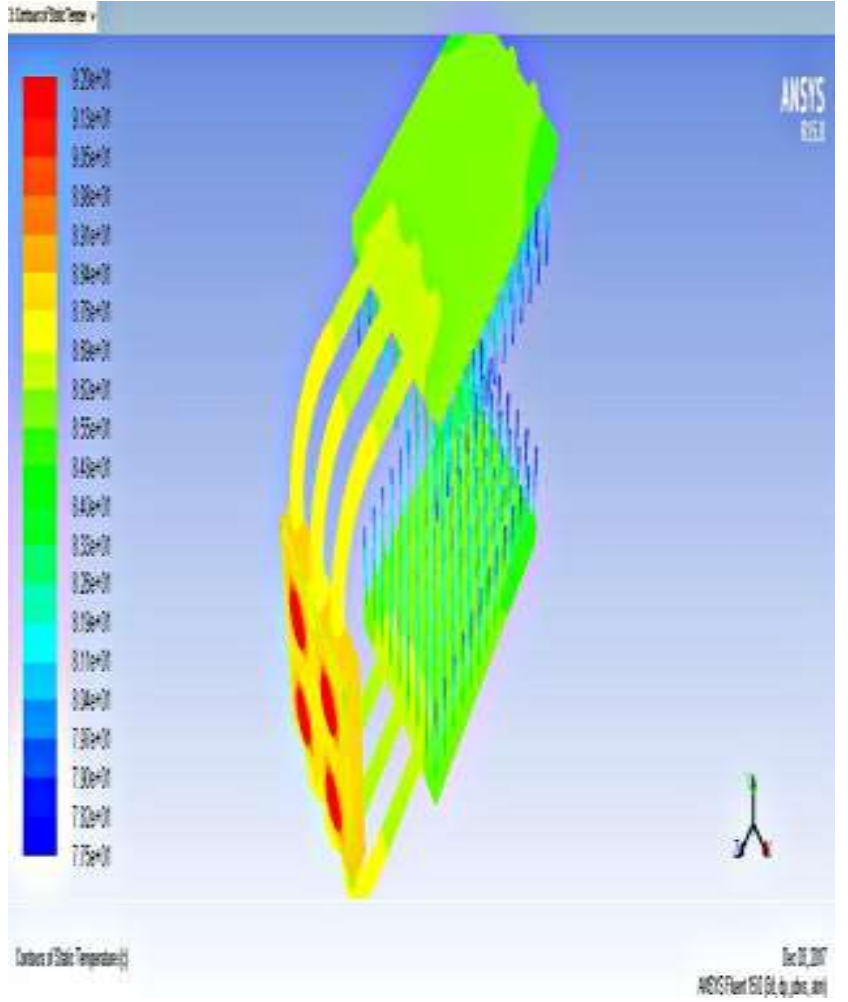

Fig-9: Temperature distribution of circular pin fin geometry

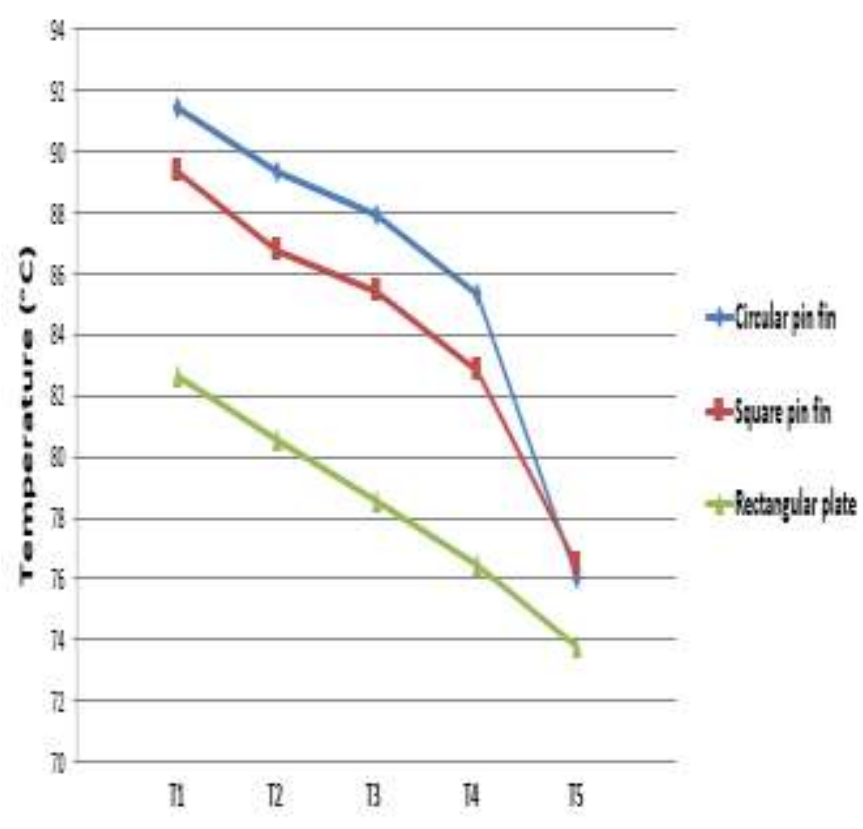

Chart-1: Temperature distribution at the stated points according to the fin profile

However, in order to analyze the effect of fin orientation on heat transfer rate, an alternative one sided outwards orientation and another alternative two sided orientation were modeled (Fig-10 and Fig-12).

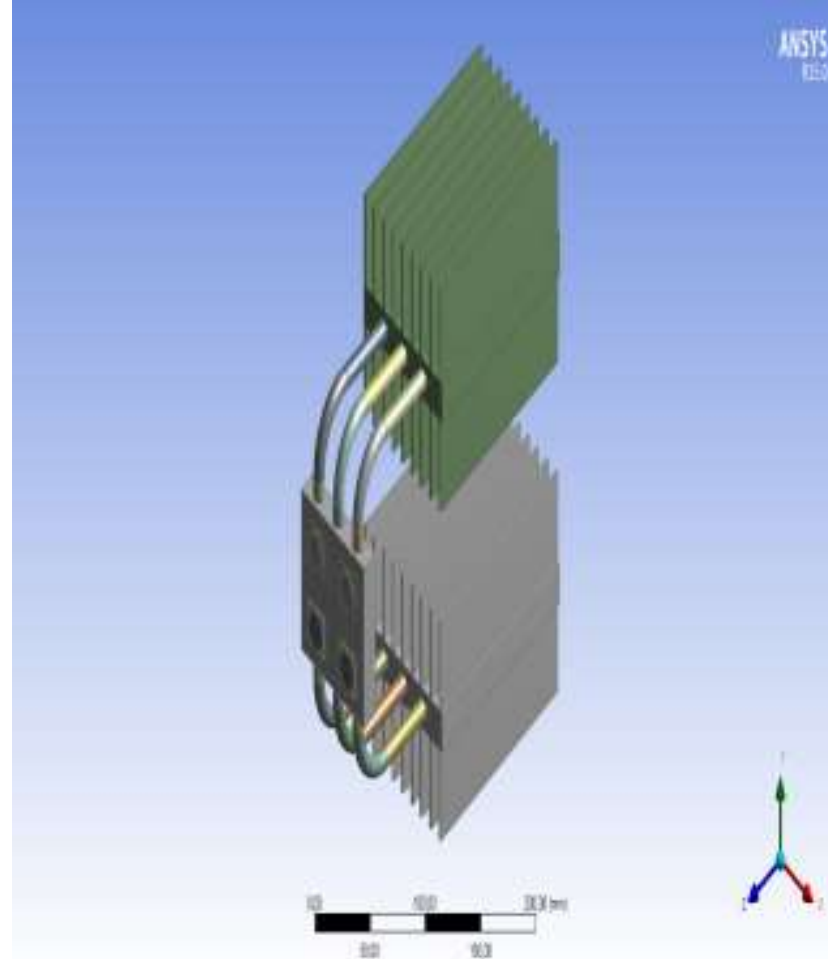

Fig-10: Two-sided fin geometry

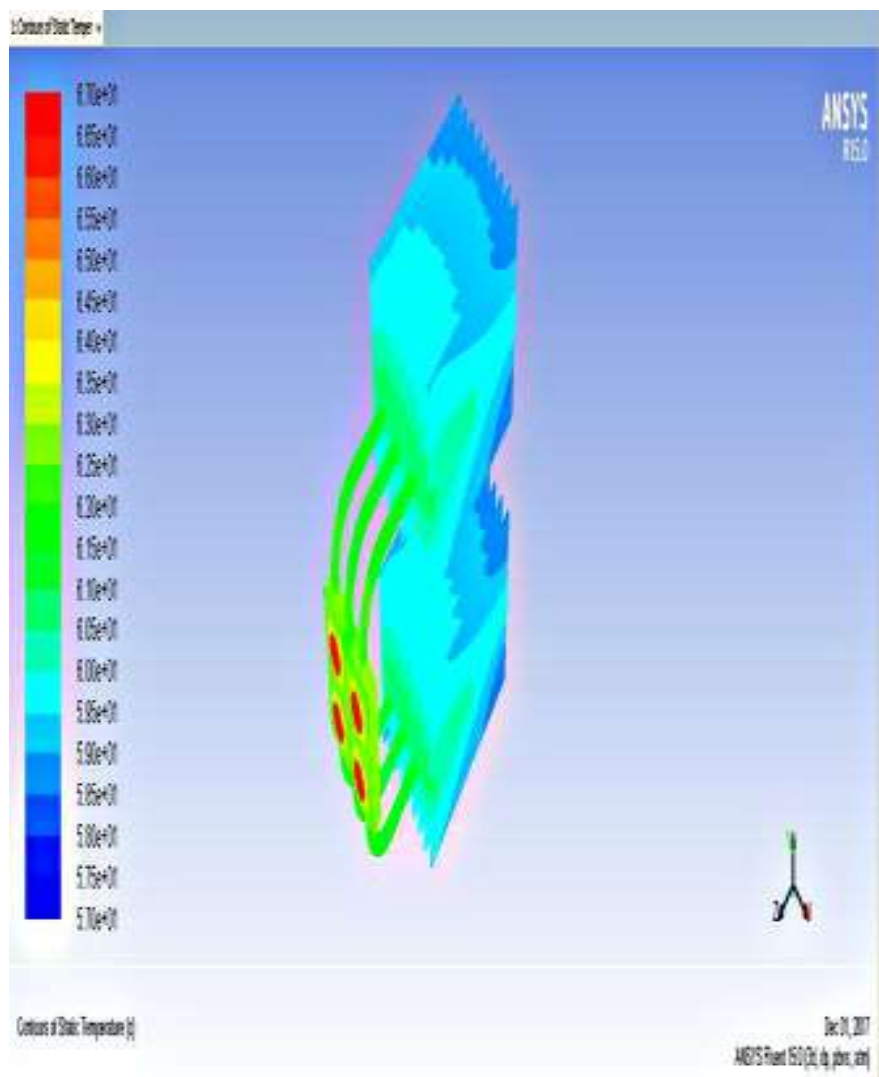

Fig-11: Temperature distribution of two-sided fin geometry 


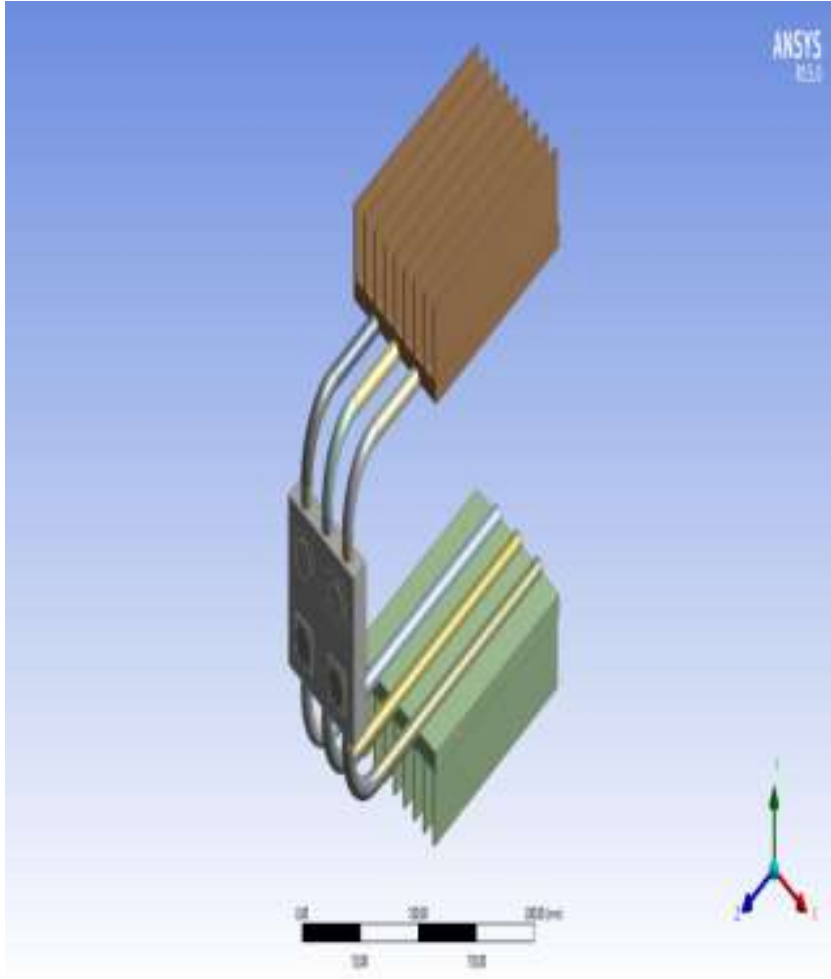

Fig-12: Outward fin geometry

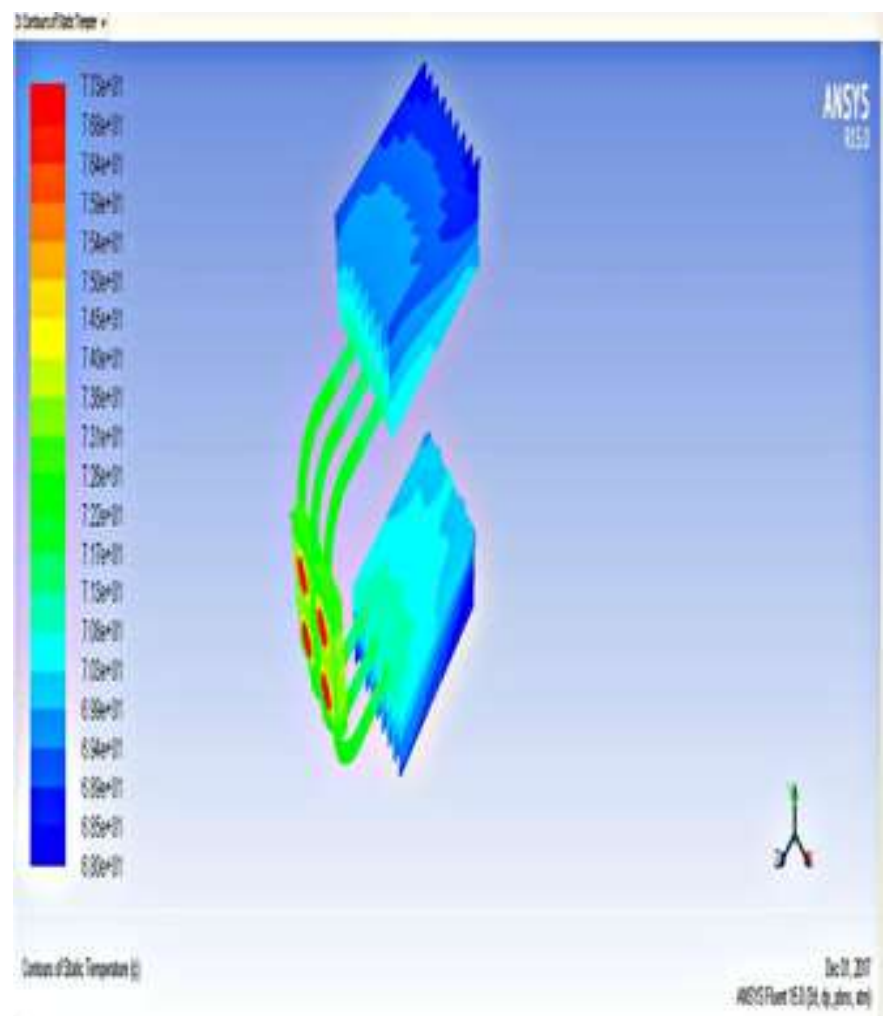

Fig-13: Temperature distribution of outward fin geometry

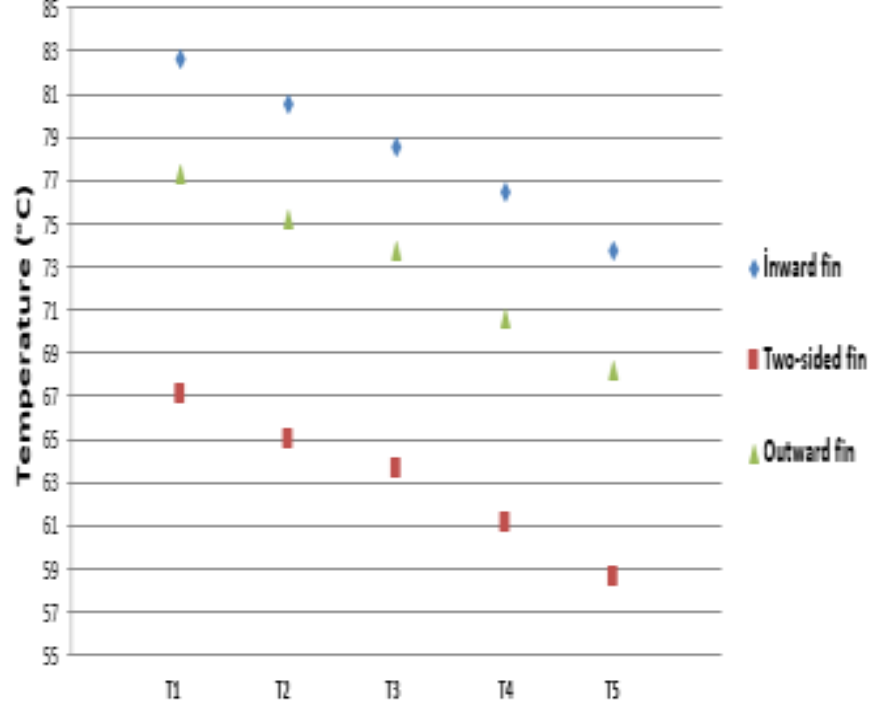

Chart-2: Temperature distribution at the stated points according to the fin orientation

Even though the heat transfer surface area is the same between outward and inward fin orientations, the outward fin orientation exhibited a higher heat transfer rate, where heat transfer rate of the two sided orientation was observed to be the highest.The results obtained in the ANSYS Fluent program are shown in Fig-11 and Fig-13.

The effect of different heat sink lengths, such as $125 \mathrm{~mm}$, $150 \mathrm{~mm}$ and $175 \mathrm{~mm}$, on the temperature distribution in the system under the same boundary conditions in ANSYS Fluent are given in Chart-3. In conclusion, it has been seen that as the length of the heat sink increases, rate of heat transfers from system to ambient increases. Similarly, in Chart-4, the effect of the fin width on the temperature distribution in the system is investigated. Fin widths varied between $2 \mathrm{~mm}$ and $3.5 \mathrm{~mm}$. Therefore, it is observed that as the fin width increases, the heat transfer rate from system to the environment increases. In Chart-5, the effect of the fin height on the temperature distribution in the system is examined. For this examination, fin heights ranging between 30-50 mm's have been modeled and analyzed.It has been seen that as the length of the fin height increases, rate of heat transfers from system to ambient increases. 


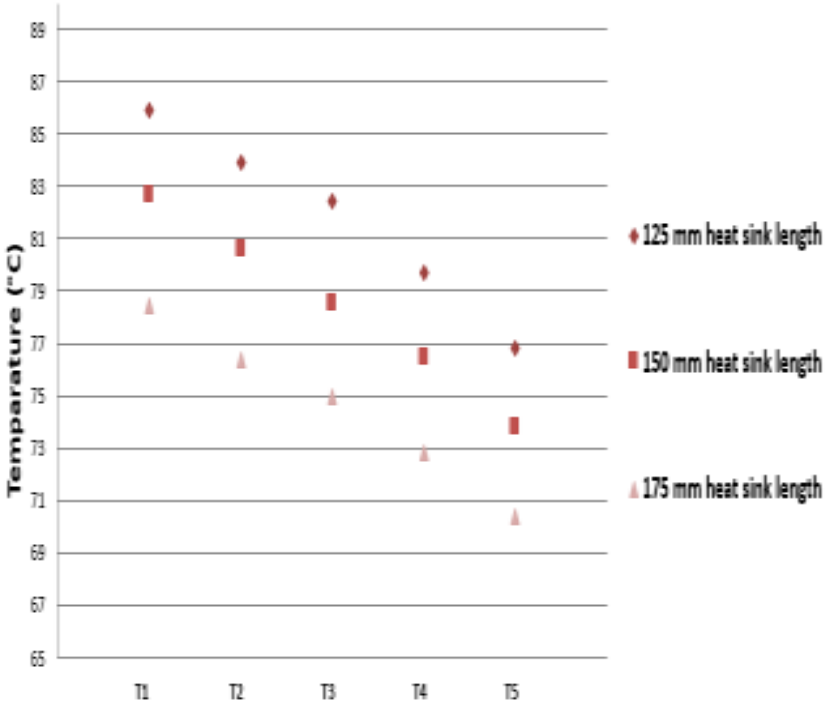

Chart-3: Temperature distribution at the stated points according to the heat sink length

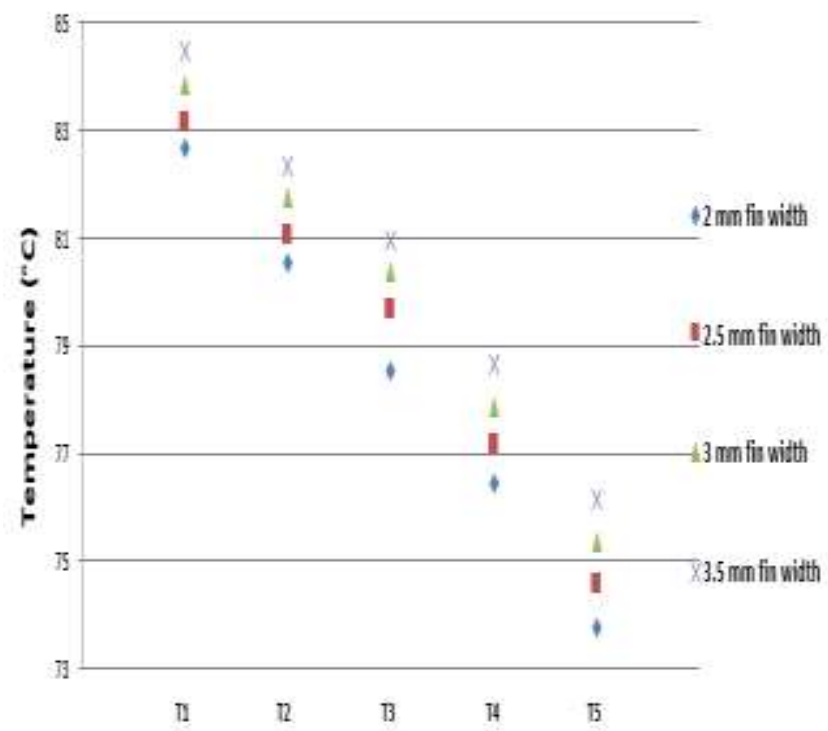

Chart-4: Temperature distribution at the stated points according to the fin width

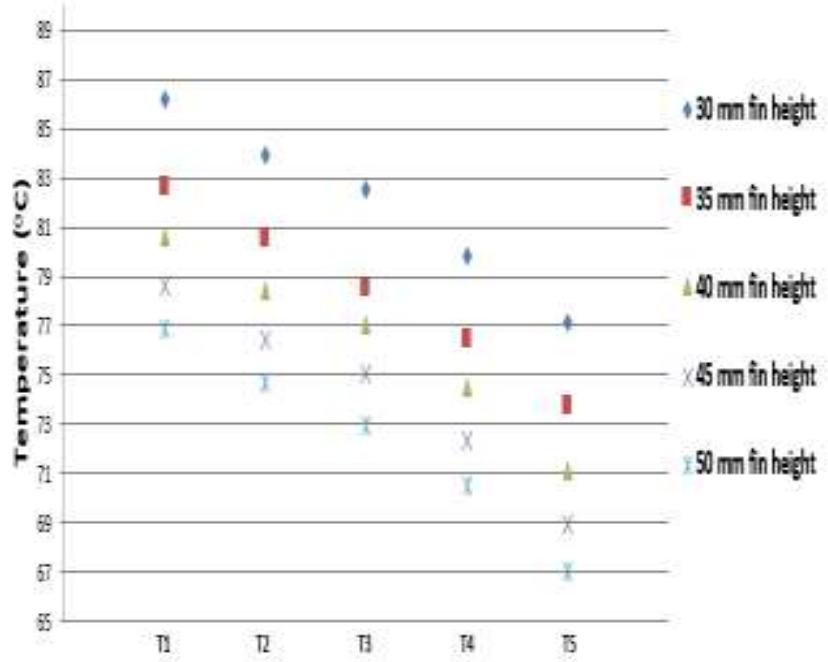

Chart-5: Temperature distribution at the stated points according to the fin height

Since the LED packages are designed for street illumination, it is a must to incorporate the effect of wind speed into the analyses. Accordingly, in Chart-6, the temperature variations in the selected points for $1 \mathrm{~km} / \mathrm{h}, 2 \mathrm{~km} / \mathrm{h}$ and 3 $\mathrm{km} / \mathrm{h}$ wind speeds are depicted.

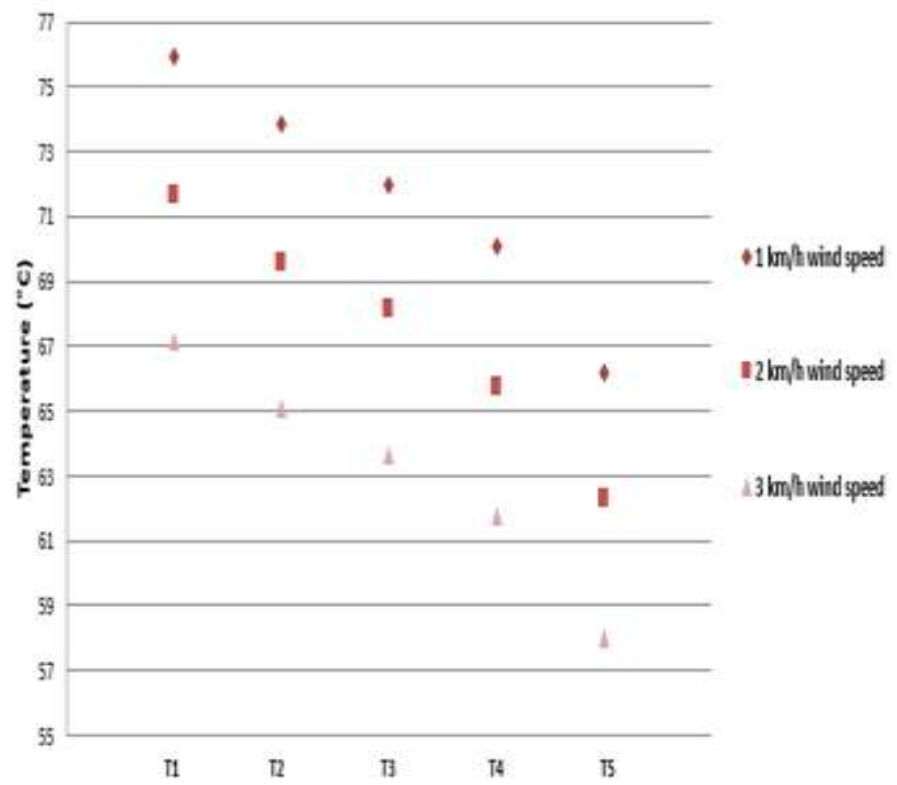

Chart-6: Temperature distribution at the stated points according to the wind speed

\subsection{Thermal Resistance}

Thermal resistance is an easy way of visualizing complex systems and analyzing some heat transfer problems by means of an electrical simulation. The concept of thermal resistance is based on an analogy with the Ohm's Law. In Fig-14, the thermal resistance network model of the designed system is depicted. According to this model, when calculating the total thermal resistance, the system is separated in to two sub-systems. Sub-system 1 is from the 
LED chip to the heat sink and its thermal resistance is designated as $\mathrm{R}_{\text {th } 1}$, whereas the sub-system 2 is the remaining part of the entire system, containing the heat pipe and the fins and its thermal resistance is designated as $R_{\text {th } 2}$

$$
\mathrm{R}_{\mathrm{th}}=\mathrm{R}_{\mathrm{th} 1}+\mathrm{R}_{\mathrm{th} 2}
$$

$\mathrm{R}_{\mathrm{LEDi}}$ stands for the omputed thermal resistance value for the LED package $i$, which is one of the 4 LED packages in the system (so $i=1,2,3,4$ ). In general, in cases where there are no external factors to affect the heat flow of the LED packages, they are placed symmetrically and they have equal thermal resistances. In the designed system, the components of the LED packages are connected in series and $\mathrm{R}_{\mathrm{LEDi}}$ is computed as Eq.(7).

$$
\mathrm{R}_{\mathrm{LEDi}}=\mathrm{R}_{1, \mathrm{i}}+\mathrm{R}_{2, \mathrm{i}}+\mathrm{R}_{3, \mathrm{i}}+\mathrm{R}_{4, \mathrm{i}}+\mathrm{R}_{5, \mathrm{i}}+\mathrm{R}_{6, \mathrm{i}}
$$

$T_{b}$ is the maximum temperature in the LED chip, $T_{e}$ is the temperature of the evaporator region of the heat pipe, $T_{c}$ is the average temperature of the condenser region and $\mathrm{T}_{\mathrm{a}}$ is the ambient temperature. Since total power input to the system is assumed to be $100 \mathrm{~W}$ and $80 \%$ of this input is assumed to be converted to heat, the total heat power input to the system is assumed to be $80 \mathrm{~W}$. Based on the assumption that total input heat power is distributed evenly among the LED packages, heat power affecting each LED package is $80 / 4=20 \mathrm{~W}$. Since the LED packages in the system are connected in parallel, Rth1 is calculated as in Eq.(8).

$$
\mathrm{R}_{\mathrm{th} 1}=\left(\sum_{\mathrm{i}=1}^{4} \frac{1}{\mathrm{R}_{\mathrm{LEDi}}}\right)^{-1}
$$

In order to calculate the total thermal resistance of the second sub - system, the necessary order of computation is $R_{h, i}$, (thermal resistance of the part of the heat pipe between the evaporator and the condenser) and then $R_{f, i}$ (thermal resistance of the part between the fins and the ambient.) Since there are $3 \mathrm{U}$-shaped heat pipes and 6 condenser regions in the system, $R_{\text {th } 2}$ is calculated according to the Eq.(9).

$$
\begin{aligned}
& \mathrm{R}_{\mathrm{th} 2}=\left(\sum_{i=1}^{6} \frac{1}{R_{h, i}+R_{f, i}}\right)^{-1} \\
& \mathrm{R}_{\mathrm{h}, \mathrm{i}}=\frac{\mathrm{T}_{\mathrm{e}}-\mathrm{T}_{\mathrm{c}}}{\mathrm{Q}_{\mathrm{i} 2}} \\
& \mathrm{R}_{\mathrm{f}, \mathrm{i}}=\frac{\mathrm{T}_{\mathrm{c}}-\mathrm{T}_{\mathrm{a}}}{\mathrm{Q}_{\mathrm{i} 2}}
\end{aligned}
$$

When calculating Rh,i and Rf,i, it is assumed that 80 / $6=13.3 \mathrm{~W}$ of heat power $\left(\mathrm{Q}_{\mathrm{i} 2}\right)$ is applied into each condenser region. In this study, based on the thermal resistance model that has just been described, the total thermal resistances for various values of the parameters are computed.

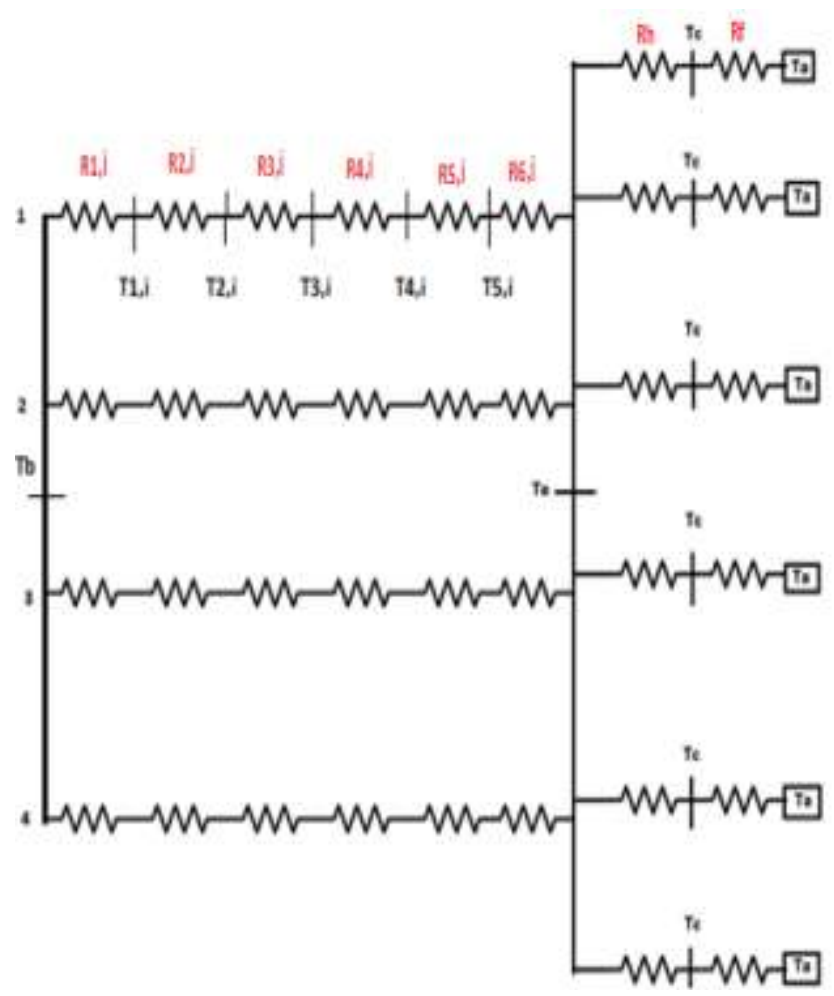

Fig-14: Thermal resistance network model of designed geometry

\subsection{Junction Temperature}

In LEDs, junction temperature is a very important parameter because some other important parameters such as LED lifespan and light flux are dependent onto it. LED junction temperature is calculated according to the Eq. (12). Total thermal resistance of the system has to be known to be able to calculate the junction temperature.

$$
\mathrm{T}_{\mathrm{j}}=\mathrm{T}_{\mathrm{a}}+\mathrm{R}_{\mathrm{th}} * \mathrm{I}_{\mathrm{F}} * \mathrm{~V}_{\mathrm{F}}
$$

$\mathrm{T}_{\mathrm{a}}$ : Ambient temperature $\left({ }^{\circ} \mathrm{C}\right)$

$\mathrm{I}_{\mathrm{F}}$ : Forward current (I)

$\mathrm{V}_{\mathrm{F}}$ : Forward voltage $(\mathrm{V})$

$\mathrm{R}_{\text {th }}$ : Total thermal resistance $\left({ }^{\circ} \mathrm{C} / \mathrm{W}\right)$

Previous researches reveal that there is a positive correlation between thermal resistance and junction temperature. In this study, the variation of thermal resistance and junction temperature with respect to the geometric parameters (i.e. fin height and width, heat sink length, fin profile and orientation) is investigated (Chart-7-11) 


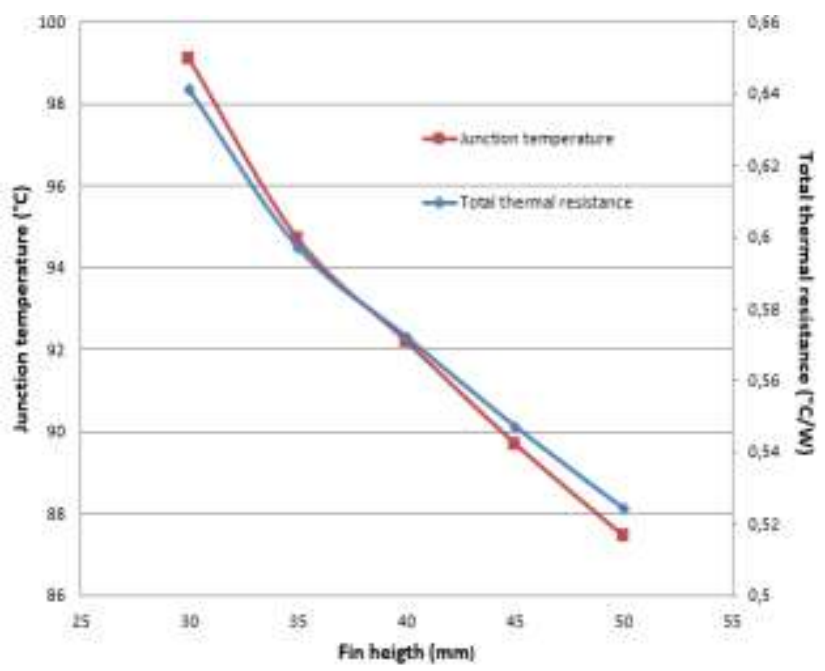

Chart-7: Variation ofjunction temperature and total thermal resistance with fins height

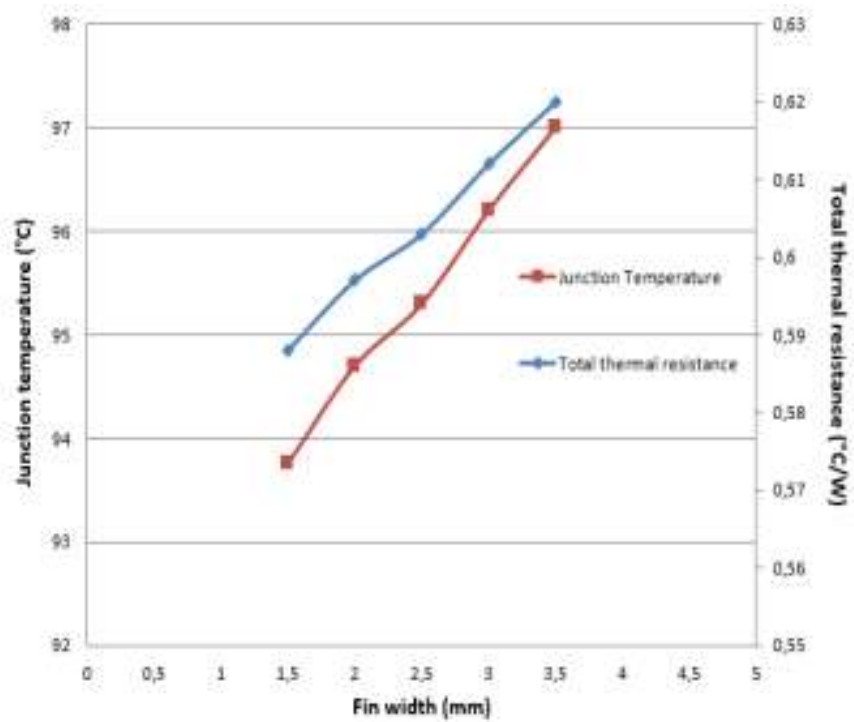

Chart-8: Variation ofjunction temperature and total thermal resistance with fins width

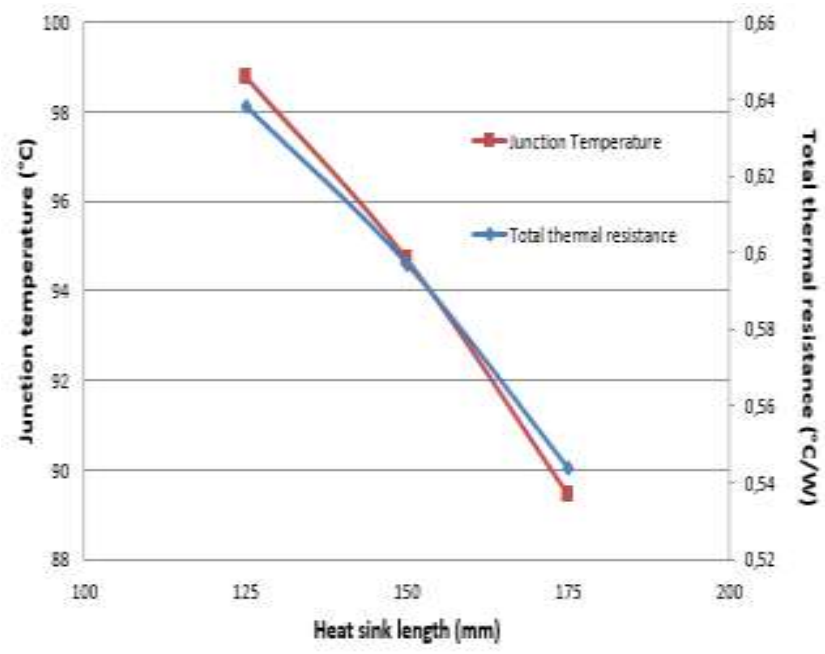

Chart-9: Variation of junction temperature and total thermal resistance with the heat sink length

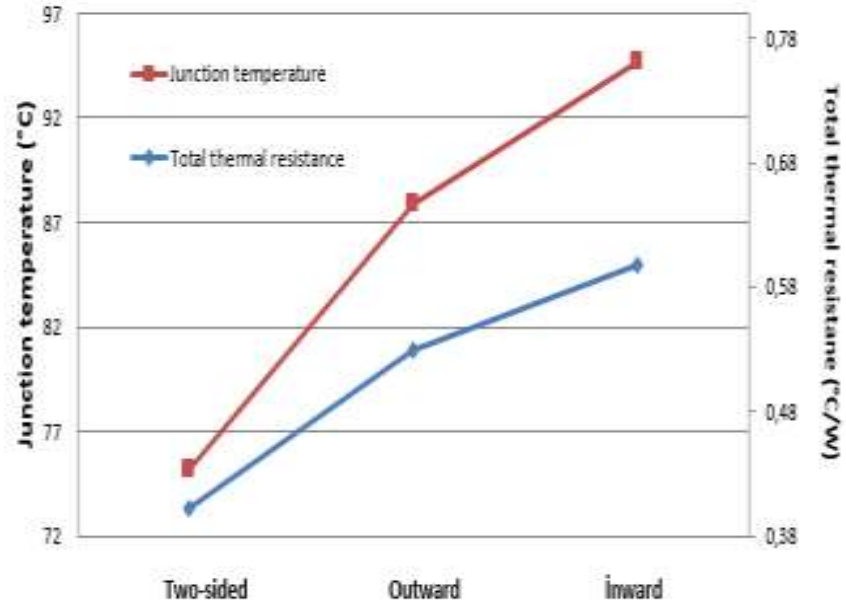

Chart-10: Variation of junction temperature and total thermal resistance with fin orientation

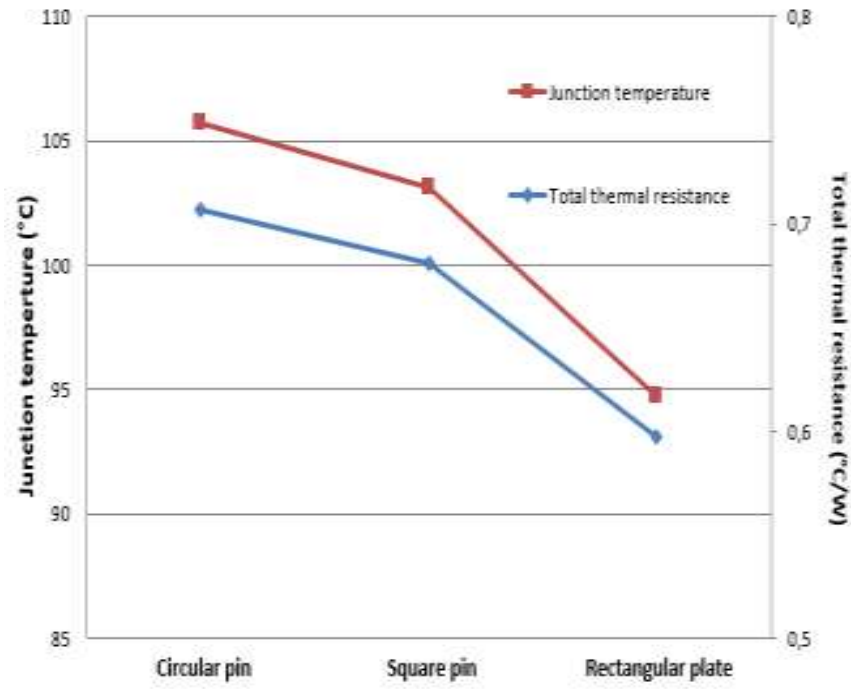

Chart-11: Variation ofjunction temperature and total thermal resistance according to fin profile

\subsection{Optimum Fin Spacing}

It is a must to determine and apply the optimum geometries of the fins on the heat sink. Fin spacing affects heat sink performance. If it is too large, the thermal boundary layers formed along the fins will be isolated. In that case, the coefficient of thermal conductivity in each fin will be equal to a singular fin under the same conditions. If it is too small, an entire overlap of the thermal boundary layers of adjacent fins will occur. In that case, only the bottom parts of the fins will conduct heat efficiently, reducing the overall efficiency of the system. Elenbaas studied on calculation of the average coefficients of thermal conductivity on the surfaces of isothermal parallel fins and determination of optimum fin spacing [11]. He also derived the equations to compute $\mathrm{Nu}$ and Ra numbers (Eq.13 and 14).

$$
\mathrm{Nu}=\frac{\mathrm{h} * \mathrm{~b}}{\mathrm{k}}=\frac{\mathrm{Ra}}{24} *\left(1-\mathrm{e}^{\frac{-35}{\mathrm{Ra}}}\right)^{0.75}
$$




$$
\mathrm{Ra}=\frac{\mathrm{q}^{2} * \mathrm{~g} * \beta * \mathrm{C}_{\mathrm{p}} * \mathrm{~b}^{4} * \Delta \mathrm{T}}{\mu * \mathrm{k} * \mathrm{~L}}
$$

In the Eq.13 and 14, $\mathrm{h}$ is the overall heat transfer coefficient, whereas, $\mathrm{k}, \mathrm{Cp}, \mu$ and $\mathrm{q}$ are the coefficient of thermal conductivity of air at the particular film temperature, specific heat of air, dynamic viscosity of air and density of air, respectively. $\Delta \mathrm{T}$ is the difference between the fin temperature and the ambient temperature. Fin spacing is $b$, heat sink length is L. When calculating the heat transfer coefficient of the fins, surface temperature is assumed to be constant. In this study, optimum geometry was sought by altering the number of fins and the fin spacing, while keeping all the other geometric parameters fixed.

By using Elenbaas formulations, the optimum fin spacing can be computed as in Eq. (15).

$$
\mathrm{b}_{\mathrm{opt}}=(2.659) *\left(\frac{\mu * \mathrm{k} * \mathrm{~L}}{\mathrm{~g} * \beta * \mathrm{C}_{\mathrm{p}} * \Delta \mathrm{T}}\right)^{0.25} * \mathrm{q}^{-0.5}
$$

In this study, the assumed constant values for fin surface temperature and ambient temperature are $75^{\circ} \mathrm{C}$ and $35^{\circ} \mathrm{C}$, respectively. Based on these, film temperature of air was calculated according to the Eq. (16).

$$
\mathrm{T}_{\mathrm{s}}=\left(\mathrm{T}_{\mathrm{s}}+\mathrm{T}_{\mathrm{a}}\right) / 2=(75+35) / 2=55^{\circ} \mathrm{C}+273.15
$$

$=328.15 \mathrm{~K}$

$$
\beta=1 / \mathrm{T}_{\mathrm{f}}=0.003047(1 / \mathrm{K})
$$

Taking $55^{\circ} \mathrm{C}$ as the film temperature, other thermophysical properties of air are read from the table [12].

$\mu=1.9855 * 10^{-5} \mathrm{Ns} / \mathrm{m}^{2}$

$\mathrm{k}=0.027715 \mathrm{~W} / \mathrm{m} . \mathrm{k}$

$\mathrm{q}=1.0755 \mathrm{~kg} / \mathrm{m}^{3}$

$\mathrm{C}_{\mathrm{p}}=1007 \mathrm{~J} / \mathrm{kg} \cdot \mathrm{K}$

$\mathrm{v}=1.847 * 10^{-5} \mathrm{~m}^{2} / \mathrm{s}$

$\operatorname{Pr}=0.7215 \mathrm{~kg} / \mathrm{m}^{3}$

By plugging the numerical values tabulated above into Eq.(15), $b_{\text {opt }}$ value is calculated as $7.38 \mathrm{~mm}$. To observe the variation of the overall heat transfer coefficient and Nusselts number, $\mathrm{h}$ and $\mathrm{Nu}$ values are calculated for every $\mathrm{b}$ (fin spacing).

In addition to Elenbaas' studies, Bar-Kohen and Rohsenow, proposed different equations for computation of $\mathrm{Nu}$ and $\mathrm{Ra}$ [13].

$$
\begin{aligned}
& \mathrm{Ra}=\frac{\mathrm{g} * \beta *\left(\mathrm{~T}_{\mathrm{s}}-\mathrm{T}_{\mathrm{a}}\right) * \mathrm{~b}^{3} * \mathrm{Pr}}{\mathrm{v}^{2}} \\
& \mathrm{Nu}=\left[\frac{576}{\left(\frac{\mathrm{Ra} * \mathrm{~b}}{\mathrm{~L}}\right)^{2}}+\frac{2.873}{\left(\frac{\mathrm{Ra} * \mathrm{~b}}{\mathrm{~L}}\right)^{0.5}}\right]^{-0.5}
\end{aligned}
$$

According to Bar - Kohen and Rohsenow (1984), optimum fin spacing is calculated by Eq.(20).

$$
\mathrm{b}_{\mathrm{opt}}=2.714 *\left(\frac{\mathrm{b}^{3} * \mathrm{~L}}{\mathrm{Ra}}\right)^{0.25}
$$

$b_{\text {opt }}$ value calculated acording to Eq.(20) is $7.53 \mathrm{~mm}$. Afterwards, by plugging the thermophysical properties of air, tabulated above, into Eq.(13) and Eq.(14), h and $\mathrm{Nu}$ numbers are calculated for every $b$ value. Values generated by doing so are compared in Chart-12 and Chart-13. This comparison shows that, as fin spacing increases, overall heat transfer coefficient increases up to some point and then converges. On the other hand, Nusselts number exhibits a continuous increase with the increasing fin spacing. The amount of heat transferred by convection is calculated by Eq.(21).

$$
\mathrm{Q}=\mathrm{h} * \mathrm{~A} * \Delta \mathrm{T}
$$

According to this equation, when the temperature gradient is constant, the amount of heat transferred is dependent on overall heat transfer coefficient and total heat transfer surface area. A trivial implication of the equation is that, as overall heat transfer coefficient increases, the total amount of heat transfer may not always increase. If there is a reduction of total heat transfer surface area that is sharper than the increase in the overall heat transfer coefficient, the total amount of heat transfer would actually decrease. Therefore, for every design of heat sink with fins, an optimum fin spacing has to be calculated. As seen in Chart15, in the calculated optimum fin spacing interval, the highest amount of heat transfer was obtained.

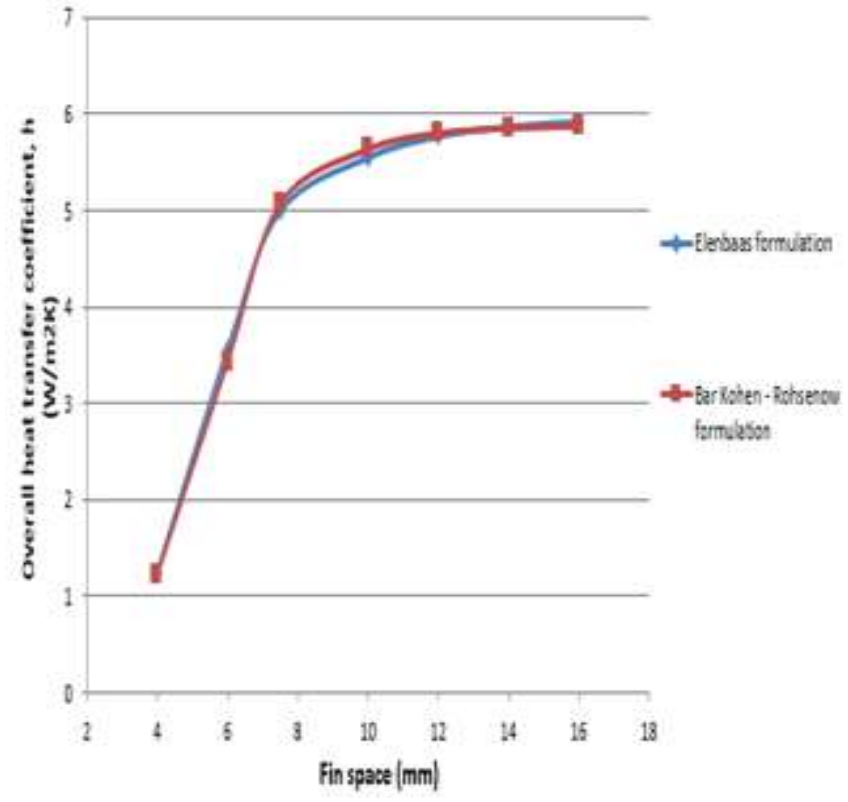

Chart-12: Variation of fin space with overall heat transfer coefficient 


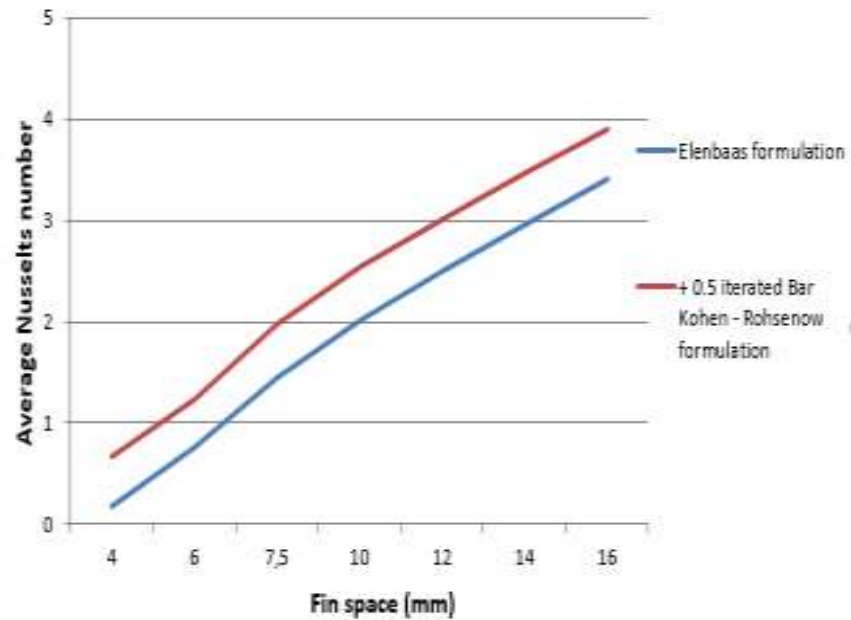

Chart-13: Effect of fin space to average Nusselts number

To validate the analytically calculated optimum fin spacing value, the system is modelled and analysed for the specified fin spacing values. The maximum temperature values versus fin spacing is plotted in Chart-14. It is observed that, there is a good fit between analytical and numerical results.

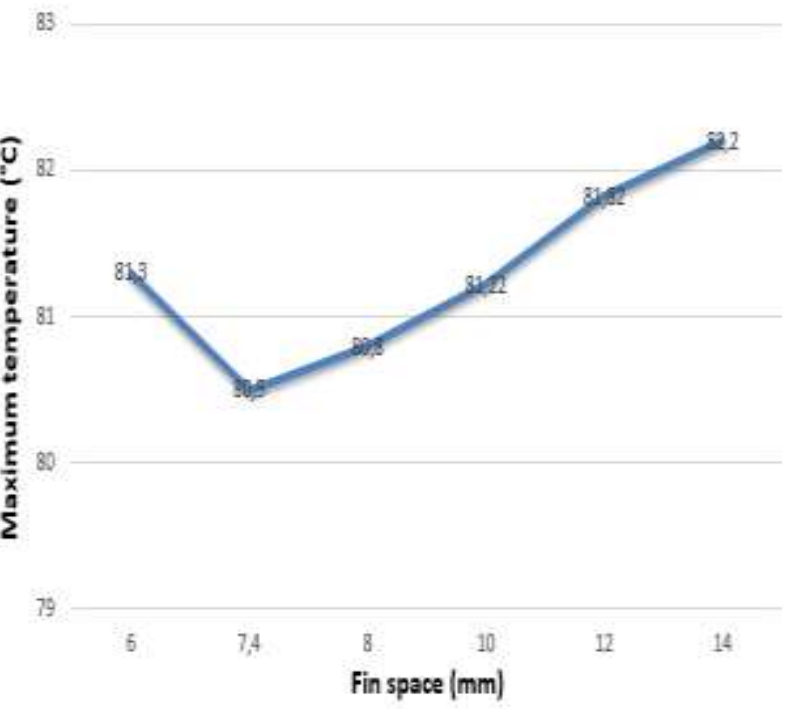

Chart-14: Variation of fin space with maximum temperature of LED package

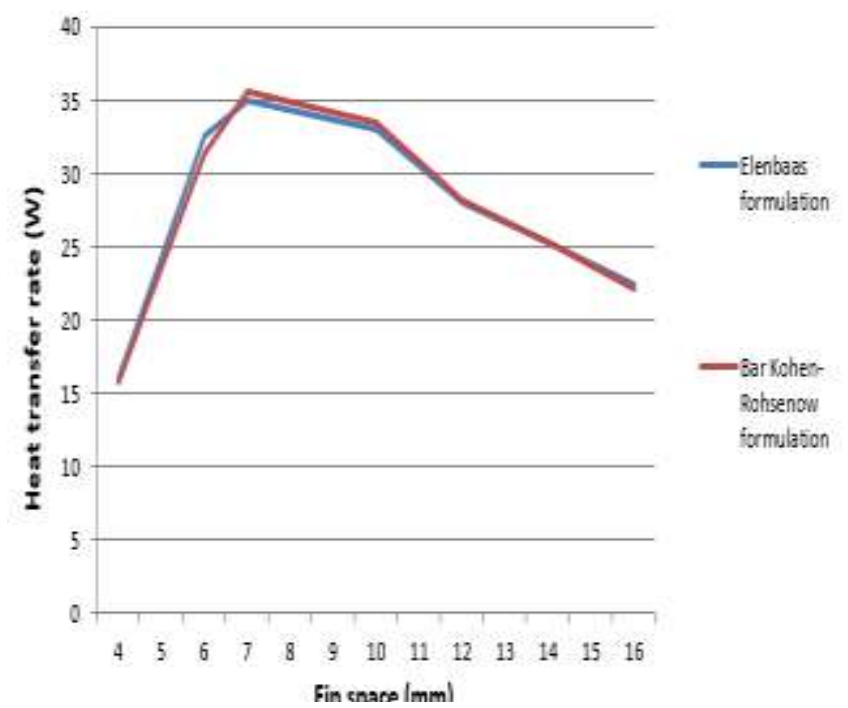

Chart-15: Effect of distance between fins to maximum temperature in LED package

\section{CONCLUSION}

The aim of this study was to produce solutions for the overheating problem in LED packages, which were designed for street illumination. For this purpose, U- shaped copper heat pipes were utilized.In order to maximise the rate of heat dissipation that the heat pipes could attain, heat sinks with fins were integrated into the heat pipes and their optimum geometries were attempted to be found.

Square pin, circular pin and rectangular fin profiles were tested and it was seen that rectangular fin model has the lowest thermal resistance. Lastly, optimum fin spacing value was determined.In conclusion, it was seen that, heat sink and fin geometries have a significant effect on heat transfer rate.

\section{REFERENCES}

[1]. Robert, T., Paynter, B.J.,2011, Toby Boydell: Introduce to Electricity. Prentice Hall published, p. 1146.

[2]. Cheng, H.H., Huang, D.S., Lin, M.T., 2012, Heat dissipation design and analysis of high power LED array using the finite element method, Microelectron. Reliab. 52, 905-911.

[3]. Kim L., Choi J. H., Jang S. H., Shin M. W., 2006, Thermal analysis of LED array systemwith heat pipe, Thermochemical Acta, Vol. 455, pp. 21-25.

[4]. Lu, X., Hua, T., Cheng, Y., 2009, Thermal Analysis of Loop Heat Pipe Used for High-Power LED, Thermochemical Acta 493,25-29.

[5]. Lin, Z., Wang, S., Huo, J., Hu, Y., Chen, J., Zhang, W., Lee, E., 2011, Heat transfer characteristics and LED heat sink application of aluminum plate oscillating heat pipes. Applied Thermal Engineering, 31(14), 2221-2229.

[6]. Shen, S.C., Huang, H.J., Shaw, H.J., 2013, Design and Estimation of a MCPCB-Flat Plate Heat Pipe for LED Array Module, Proceedings of 2013 IEEE International 
Conference on Mechatronics and Automation August 4 - 7, Takamatsu, Japan.

[7]. Channamallikarjun, 2014, Thermal analysis of CPU with variable base plate heat-sink using CFD, International Journal of Research in Engineering and Technology, 3, 510 -515 .

[8]. Tang, Y., Ding, X., Li, Z., Li, B., 2014, A high power LED device with chips directlymounted on heat pipes, Applied Thermal Engineering 66- 632-639.

[9]. Schmid, G., Huang, Z. L., Yang, T. H., Chen, S. L.,2017, Numerical analysis of a vertical double-pipe singleflow heat exchanger applied in an active cooling system for high-power LED street lights. Applied Energy, 195, 426438.

[10]. Wang, M., Tao, H., Sun, Z., Zhang, C.,2017, The development and performance of the high power LED radiator. International Journal of Thermal Sciences, 113, 6572.

[11]. Elenbaas, W. 1942, Heat dissipation of parallel plates by free convection. Physica, 9(1), 1-28.

[12]. Yunus, C. A., \&Afshin, J. G., 2011, Heat andmass transfer: fundamentals and applications. McGraw-Hill, 488489.

[13]. Bar-Cohen, A., and Rohsenow, W., 1984, Thermally Optimum Spacing of Vertical, Natural Convection Cooled, Parallel Plates, ASME J. Heat Transfer, 106, pp. 116-122. 